\title{
A practical indicator for surface ocean heat and freshwater buoyancy fluxes and its application to the NCEP reanalysis data
}

\author{
By Johannes Karstensen ${ }^{1 \star}$, Katja Lorbacher ${ }^{1,2}$ \\ ${ }^{1}$ Leibniz-Institut für Meereswissenschaften, IFM-GEOMAR, Düsternbrooker Weg 20, 24105 Kiel, Germany; \\ ${ }^{2}$ now at: CSIRO-CMAR, Private Bag 1, Aspendale, VIC 3195, Australia
}

(Manuscript received 30. March 2010; in final form 30. November 2010)

\begin{abstract}
The buoyancy flux at the air/sea interface plays a key role in water mass transformation and mixing as it modifies surface water density and in turn drives overturning and enhances stratification. It is the interplay of these two independent heat and freshwater buoyancy flux components that is of central importance when analysing mechanisms of the ocean/atmosphere interaction. Here, a diagnostic quantity $\left(\Theta_{B}\right)$ is presented that allows to capture the relative contribution of both components on the buoyancy flux in one single quantity. Using NCEP reanalysis of heat and freshwater fluxes (1948-2009) demonstrates that $\Theta_{B}$ is a convenient tool to analyse both the temporal and spatial variability of their corresponding buoyancy fluxes. For the global ocean the areal extent of buoyancy gain and loss regions changed by $10 \%$, with the largest extent of buoyancy gain during the 1970 to 1990 period. In the subpolar North Atlantic, and likewise in the South Pacific, decadal variability in freshwater flux is pronounced and, for the latter region, takes control over the total buoyancy flux since the 1980's. Some of the areal extent time series show a significant correlation with large-scale climate indices.
\end{abstract}

\section{Introduction}

The ocean's surface layer is stirred by the wind and undergoes a cycle of convection and restratification in response to changes in surface water density. The surface water density is modified by the surface density flux $\left(\mathrm{Q}_{\rho}\right)$ that is composed of a heat flux $\left(\mathrm{F}_{\mathrm{T}}\right)$ scaled by the thermal expansion coefficient $(\alpha)$, and a freshwater flux $\left(\mathrm{F}_{\mathrm{S}}\right)$ scaled by the haline contraction coefficient $(\beta)$. Multiplying the sum of the scaled fluxes with the sea surface density $\left(\rho_{S}\right)$ results in the surface ocean density flux (e.g. Schmitt et al., 1989; Zhang and Talley, 1998):

$$
\mathrm{Q}_{\rho}=\rho_{S}\left(\alpha \mathrm{F}_{\mathrm{T}}+\beta \mathrm{F}_{\mathrm{S}}\right),
$$

\footnotetext{
* Corresponding author.

e-mail: jkarstensen@ifm-geomar.de
}

(c) 0000 Tellus 


$$
\text { where } \mathrm{F}_{\mathrm{T}}=-\mathrm{Q}_{\mathrm{net}} / \rho_{\mathrm{S}} \mathrm{c}_{\mathrm{p}} \text { and } \mathrm{F}_{\mathrm{S}}=(\mathrm{E}-\mathrm{P}) \cdot \mathrm{S} /(1-\mathrm{S} / 1000) \text {. }
$$

In the above equations, $\mathrm{Q}_{\text {net }}$ is the net heat flux (negative if ocean loses heat), $\mathrm{E}-\mathrm{P}$ the local evaporation minus precipitation balance (assuming no influence from run-off and ice sheet melting), $\mathrm{c}_{\mathrm{p}}$ the specific heat of seawater, and S the sea surface salinity.

Considering the gravitational acceleration $g$ and a reference density $\rho_{0}$, the surface density flux becomes a buoyancy flux $\mathscr{B}=-g \mathrm{Q}_{\rho} / \rho_{0}$ in units $\mathrm{W} \mathrm{kg}^{-1}$. The minus sign indicates that a water parcel becomes less buoyant when it gains density. Therefore, $\mathscr{B}$ drives overturning $(\mathscr{B}<0)$ or stratification $(\mathscr{B}>0)$ of surface waters and is thus ultimately related to the formation and destruction of water masses at the ocean surface (e.g. Walin, 1982; Tziperman, 1986). The distribution of $\mathscr{B}$ has been studied in theoretical studies (Garrett et al., 1995; Nurser et al., 1999), for the North Atlantic basin (e.g. Schmitt et al., 1989; Speer, 1997), the Southern Ocean (e.g. Marshall, 1997; Speer et al., 2000; Badin and Williams, 2010), shelf seas (Badin et al., 2010, and references therein), and on global scales (e.g. Speer et al., 1995; Zhang and Talley, 1998).

$\mathscr{B}$ is a quantity that is typically calculated from atmospheric and oceanic parameters at their interface, the sea surface. As such, atmospheric and ocean variability both reflect on $\mathscr{B}$ in a composite way, making $\mathscr{B}$ an important parameter to analyse variability of the atmosphere/ocean system. Changes in atmospheric forcing over the oceans, e.g. as a response to climate variability, can influence the air/sea exchange and thereby leave an imprint in the ocean. Likewise, changes in ocean circulation, e.g. the intensity of the northward residual circulation in the Southern Ocean (Badin and Williams, 2010), may influence the air/sea temperature difference, and thereby the heat flux and buoyancy flux accordingly.

Although $\mathscr{B}$, over a larger part of the ocean area, is dominated by its thermal component $\left(\mathscr{B}_{\mathrm{T}}\right)$, it is the interplay of $\mathscr{B}_{\mathrm{T}}$ with the haline component $\left(\mathscr{B}_{\mathrm{S}}\right)$ that ultimately determines the impact of atmospheric and ocean changes on the ocean ventilation and subsequently the interior ocean structure. (Note: buoyancy flux is not the single driver for interior ocean water mass renewal, and processes, such as mixing, act as transmitters of surface information to propagate into the ocean's interior.)

Most studies on surface ocean buoyancy forcing put a focus on $\mathscr{B}_{\mathrm{T}}$. One possible reason is that seasonal buoyancy flux variability is often controlled by heat flux variability, including the changes in the thermal expansion coefficient (Large and Nurser, 2001). However, it is well established from observations (e.g. Fairbanks, 1989) and model experiments (e.g. Vellinga and Wood, 2002) that $\mathscr{B}_{\mathrm{S}}$ is crucial for long-term variability of the atmosphere/ocean system and as such it is mandatory to consider both, heat and freshwater forcing.

Methods to conduct a joint analysis of spatially distributed time series of heat and freshwater buoyancy fluxes are rather limited: Either one has to apply a temporal averaging or an areal averaging to analyse the spatial distribution and temporal evolution of the two flux components, respectively. A different approach is analysing the flux ratio $\left(\mathscr{B}_{\mathrm{T}} / \mathscr{B}_{\mathrm{S}}\right.$; Zhang and Talley, 1998; Schmitt et al., 1989). The advantage of a ratio is that it combines the two flux components into a single number which opens the way for a joint analysis of the two components. But a ratio has obvious disadvantages for description and analysis: (1) a ratio is ambiguous, in case both contributors are either negative or positive the ratio is always positive - although the total flux is fundamentally different $(\mathscr{B}<0$ versus $\mathscr{B}>0)$. (2) The ratio goes to infinity in case the flux in the denominator goes to zero, while the total flux can still be well defined. (3) The flux magnitude of either one or the other components is scaled differently as the numerator is the main contributor for ratios between -1 and 1 , and the denominator is the main contributor for ratios between $\pm \infty$ and \pm 1 .

Here we introduce a diagnostic that considers the relative contribution of the heat and freshwater buoyancy flux components but require neither temporal nor spatial averaging and also overcomes the disadvantages of a ratio. The diagnostic uses calculating the phase angle of the flux components as $\operatorname{atan} 2\left(\mathscr{B}_{\mathrm{T}}, \mathscr{B}_{\mathrm{S}}\right)$. As Figure 1 illustrates, the $\operatorname{atan} 2$ is a two-argument function, available in most mathematical computation packages, that computes the angle between the positive x-axis of a plane (here $\mathscr{B}_{\mathrm{S}}$, Figure 1) and the point $(\mathrm{x}, \mathrm{y})$ (here $\left(\mathscr{B}_{\mathrm{S}}, \mathscr{B}_{\mathrm{T}}\right)$ ) on it. (Note that for most software packages the input arguments are defined as such that the y-axis is the first input argument $(\operatorname{atan} 2(y, x))$.)

For practical reasons it is convenient to associate a negative angle with a negative total buoyancy flux (which is similar to a buoyancy loss) and therefore the phase angle from the atan 2 function must be

(c) 0000 Tellus, 000, 000-000 
shifted by $+\pi / 4$ (see Figure 1). Because of the shift, absolute jumps greater than $\pi$ should be shifted to their $2 \pi$ complements. In the following we shall refer to the shifted phase angle as 'buoyancy flux angle'

$\Theta_{B}=\operatorname{atan} 2\left(\mathscr{B}_{T}, \mathscr{B}_{S}\right)+\frac{\pi}{4}$.

$\Theta_{B}$ divides in eight segments between $-\pi$ and $\pi$ that represent all eight possible combinations of $\mathscr{B}_{\mathrm{T}}$ and $\mathscr{B}_{\mathrm{S}}$ (Figure 1 and Table 1 ). Segments $\mathrm{S} 1$ to $\mathrm{S} 4$ represent all $\mathscr{B}_{\mathrm{T}}$ and $\mathscr{B}_{\mathrm{S}}$ combinations that in total lead to a buoyancy loss $(\mathscr{B}<0)$ of surface waters, while segment S5 to S8 represent the combinations that lead in the sum to a buoyancy gain $(\mathscr{B}>0)$. The segments S1, S2 and S5, S6 are those where the haline buoyancy flux dominates the total buoyancy flux $\left(\left|\mathscr{B}_{\mathrm{S}}\right|>\left|\mathscr{B}_{\mathrm{T}}\right|\right)$, and consequently the remaining segments indicate the dominance of the thermal flux. As $\Theta_{B}$ is an angular measure it is not meaningful to average $\Theta_{B}$ values, instead the $\mathscr{B}_{\mathrm{T}}$ and $\mathscr{B}_{\mathrm{S}}$ input data should be averaged (if required).

The following section discusses the global distribution of $\Theta_{B}$. It will be demonstrated how $\Theta_{B}$ can be used to analyse and interpret temporal variability of $\mathscr{B}_{\mathrm{T}}$ and $\mathscr{B}_{\mathrm{S}}$ in a joint way. Conclusions are drawn in the last section.

\section{Global distribution and variability of the buoyancy flux angle $\Theta_{B}$}

We make use of 62 years (January 1948 to December 2009) of monthly NCEP reanalysed atmospheric data (Kalnay et al., 1996) combined with observations time series of sea surface temperature (SST) for the same period (Reynolds et al., 2002; Smith et al., 2008) to calculate $\Theta_{B}$. For sea surface salinity, a climatology (Levitus et al., 1994) was used as no time series with global coverage is available.

From the long-term mean of the monthly heat and freshwater buoyancy fluxes (Figure 2a,b) we calculate the global distribution of $\Theta_{B}$ (Figure 3). Interannual variability is calculated from annual averages of monthly $\mathscr{B}_{\mathrm{T}}$ and $\mathscr{B}_{\mathrm{S}}$ data. Because of the non-linearity of $\alpha$ and $\beta$ on temperature and salinity, respectively, it is important to calculate the buoyancy fluxes prior to doing the averaging.

\subsection{Long-term mean $\Theta_{B}$ distribution}

At first glance, the climate pattern of $\Theta_{B}$ (Figure 3) shows many similarities with the distributions of $\mathscr{B}_{\mathrm{T}}$ and $\mathscr{B}_{\mathrm{S}}$ (Figure 2a,b). One obvious difference is that regions with strong $\mathscr{B}_{\mathrm{T}}$, like the western boundary current regions (see Figure 2a), are not peculiar in $\Theta_{B}$. By definition, $\Theta_{B}$ is uneffected by the magnitude of $\mathscr{B}$, and the dominance of $\mathscr{B}_{\mathrm{T}}$ over $\mathscr{B}_{\mathrm{S}}$ in the western boundary current regions continues eastward over large parts of the adjacent subtropical gyres. Likewise, the pattern of the ratio $\mathscr{B}_{\mathrm{T}} / \mathscr{B}_{\mathrm{S}}$ (Figure 2c) show similarities with $\Theta_{B}$ (Figure 3). However, one can identifiy regions were ambiguity appears and very large or even vanishing flux ratios appear. The interpretation of the time series will demonstrate the difficulties in operating with a non-symmetric scale.

Overall we find in the NCEP reanalysis data an equal partition of the surface ocean area into buoyancy loss (S1-S4) and buoyancy gain (S5-S8) regions (see Table 1, last row). Furthermore, $71 \%$ of the surface ocean is predominately controlled by the thermally driven buoyancy loss (S3, S4) and buoyancy gain (S7, S8), confirming the common global mean picture of two-thirds thermal and one-third haline surface buoyancy forcing (Speer et al., 1995, see Table 1).

Considering individual segments, $25 \%$ of the global ocean area is occupied by S3, indicating a net heat loss is enforced by net evaporation (compare also Figure 2a,b). Large parts of the subtropical gyres are associated with S3 where the world oceans' Central Waters are being formed (Sverdrup et al., 1942). The second largest portion is S7, covering $20 \%$ of the global ocean area in the NCEP reanalysis data. This segment indicates a buoyancy gain of surface waters which stems from warming as well as freshening effects. S7 occupies a major part of the tropical upwelling regions, parts of the North Pacific subpolar gyre and most areas in the transition region between the southern hemisphere subtropical gyres and the Antarctic Circumpolar Current.

S8 (net buoyancy gain) and S4 (net buoyancy loss) occupy about 15\% and 11\%, respectively, of the ocean's area. In both segments the haline buoyancy forcing opposes the thermal buoyancy forcing, whilst the latter has the larger amplitude.

(C) 0000 Tellus, 000, 000-000 
S8 areas indicate that a net buoyancy gain $(\mathscr{B}>0)$ occurs from the warming of surface waters $\left(\mathscr{B}_{\mathrm{T}}>0\right)$ but also that these regions lose buoyancy through net evaporation $\left(\mathscr{B}_{\mathrm{S}}<0\right)$. This is a typical situation for the eastern boundary upwelling regions and for the equatorial "cold tongue" regions in the eastern tropical Pacific and Atlantic Ocean.

S4 areas are of particular interest as here the net heat loss drives overturning of surface waters but a net freshwater gain is imprinted as a low salinity signature onto the overturning waters. This segment is found in the temperate regions of the subpolar North Atlantic and in the Mode and Intermediate Water formation areas at the poleward rim of the subtropical gyres (McCartney, 1977; Hanawa and Talley, 2001). Other regions with S4 characteristics are transition zones between the tropical and subtropical Pacific and Indian Oceans at about $10^{\circ} \mathrm{N} / \mathrm{S}$ (e.g. Tomczak and Godfrey, 1994).

In the area south of about $60^{\circ} \mathrm{S}$, haline buoyancy fluxes dominate the buoyancy forcing of surface waters, as indicated by S5 (with opposing heat loss) and S6 (with accompanying heat gain). This net heat gain in $\mathrm{S} 6$ can be related to the northward advection of cold waters with the residual circulation (e.g. Speer et al., 2000; Badin and Williams, 2010) or by other processes, such as upwelling of cold interior waters.

Finally, the $\mathscr{B}<0$ areas dominated by haline driven buoyancy loss (S1, S2) are the eastern parts of the subtropical gyres, outside of the coastal upwelling regions. In these areas intense evaporation $\left(\mathscr{B}_{\mathrm{S}}<0\right)$ controls the net buoyancy loss and thus sinking of surface waters. Depending on the local advection and mixed layer entrainment, the thermal buoyancy flux support $\left(\mathscr{B}_{\mathrm{T}}<0\right)$ or oppose $\left(\mathscr{B}_{\mathrm{T}}>0\right)$ the haline buoyancy loss. These areas are associated with the formation of saline Subtropical Underwater and eastern Subtropical Mode Waters (Mamayev, 1975; Emery and Meincke, 1986; Hanawa and Talley, 2001).

\subsection{Analysis of surface ocean buoyancy flux time series by using $\Theta_{B}$}

Time series of buoyancy flux at the sea surface and the relative importance of its two components $\mathscr{B}_{\mathrm{T}}$ and $\mathscr{B}_{\mathrm{S}}$ can be systematically and simultaneously analysed by using $\Theta_{B}$. Here we use time series of areal occupation of the eight segments, thereby eliminating the need for temporal or spatial averaging. This is in contrast to constructing time series of the individual fluxes or of their flux ratio which always require areal averaging. Three example areas are selected, the subpolar North Atlantic (Box 1), the South Pacific (Box 2) and the global ocean south of $70^{\circ} \mathrm{N}$ (see Figure 3). The $\Theta_{B}$ analysis is presented and also the areal averaged $\mathscr{B}_{\mathrm{T}}, \mathscr{B}_{\mathrm{S}}$, and their ratio $\left(\mathscr{B}_{\mathrm{T}} / \mathscr{B}_{\mathrm{S}}\right)$ for reference purposes. The discussion of the time series includes the correlation with large-scale global climate indices as the North Atlantic Oscillation (NAO; Hurrell and Deser, 2009, December through March index based on the difference of normalized sea level pressure between Lisbon, Portugal and Stykkisholmur/Reykjavik, Iceland), the Southern Annular Mode (SAM; Marshall, 2003, observation based index), the Pacific Decadal Oscillation (PDO; Zhang et al., 1997, leading PC of monthly SST anomalies in the North Pacific Ocean, poleward of $20^{\circ} \mathrm{N}$ ), and the East Atlantic pattern (EAP; Josey and Marsh, 2005, Rotated Principal Component Analysis applied to NCEP/NCAR reanalysis data).

Variability of heat and freshwater forcing in Box 1, in the subpolar North Atlantic, has been extensively discussed in the literature before (Reverdin et al., 2002; Josey and Marsh, 2005). Josey and Marsh (2005) analysed evaporation and precipitation anomalies in Box 1 for the period 1958 to 2002 (also using the NCEP reanalysis). They found not only a significant increase in net precipitation but a highly negative correlation with sea surface salinities. The EAP was found to be well correlated with the increase in precipitation while the NAO seems to play only a minor role (see also Reverdin et al., 2002). The subpolar North Atlantic is a major water mass formation area with deep reaching overturning of surface waters during winter, and therefore the freshening is not confined to the surface waters but also propagates into the interior ocean (Josey and Marsh, 2005; Curry and Mauritzen, 2005).

Time series of $\mathscr{B}_{\mathrm{T}}, \mathscr{B}_{\mathrm{S}}$ and $\mathscr{B}$ averaged over Box 1 (Figure 4, upper left) show that in the annual mean net buoyancy loss $(\mathscr{B}<0)$ is dominated by $\mathscr{B}_{\mathrm{T}}$ (cooling). $\mathscr{B}_{\mathrm{S}}$ is one order of magnitude smaller and mostly opposite to $\mathscr{B}_{\mathrm{T}}$ (except for 1969,1970$) . \mathscr{B}_{\mathrm{T}}$ shows interannual variability with no obvious trend while $\mathscr{B}_{\mathrm{S}}$ may contain more of a decadal fluctuation with an overall trend towards increasing buoyancy gain (freshwater gain), in accordance with earlier investigations (Reverdin et al., 2002; Josey and Marsh,

(c) 0000 Tellus, 000, 000-000 
2005). The buoyancy flux ratio (Figure 4, upper right) clearly shows for all years that the dominance of $\mathscr{B}_{\mathrm{T}}$ as $\left|\mathscr{B}_{\mathrm{T}} / \mathscr{B}_{\mathrm{S}}\right|$ is always greater 1 . For the years 1969 and $1970, \mathscr{B}_{\mathrm{S}}$ changed sign as evaporation dominated the freshwater flux in the areal average.

The time series of the eight $\Theta_{B}$ segments (Figure 4, lower panels) also shows, as expected, the dominance of $\mathscr{B}_{\mathrm{T}}$ buoyancy loss as well as an opposing $\mathscr{B}_{\mathrm{S}}$ buoyancy gain (S4) in Box 1. In addition the $\Theta_{B}$ analysis shows that on average $16 \%$ of the area in Box 1 is under the influence of S3 $\left(\mathscr{B}_{\mathrm{S}}\right.$ and $\mathscr{B}_{\mathrm{T}}$ are both negative) and that the variability of areal occupation of S3 and S4 are mirror images of each other. What seem to be exceptional years (1969 and 1970) from the areal average $\mathscr{B}_{\mathrm{T}}, \mathscr{B}_{\mathrm{S}}$ and their ratio show up as decadal variability with long-term trends in S3 and S4 in the $\Theta_{B}$ analysis. The positive (negative) correlation between the time series of segment S3 (S4) and EAP amounts to 0.3, significant at a $95 \%$ level. S4 is also positively correlated with the PDO by 0.3 (95\% significance level). No significant correlation (on $95 \%$ level) between any segment and the NAO was found.

The second area (Box 2 in Figure 3) examined in greater detail is the formation region of Antarctic Intermediate Water (AAIW) in the eastern South Pacific from $55^{\circ} \mathrm{S}$ to $70^{\circ} \mathrm{S}$ (McCartney, $1977 ; 1982$; Hanawa and Talley, 2001). The areal average $\mathscr{B}_{\mathrm{S}}$ and $\mathscr{B}_{\mathrm{T}}$ buoyancy fluxes (Figure 5, upper left) are of comparable magnitude, except for some short periods of opposite sign $\left(\mathscr{B}_{\mathrm{S}}>0, \mathscr{B}_{\mathrm{T}}<0\right)$. $\mathscr{B}_{\mathrm{S}}$ nearly doubled in magnitude with a rather linear increase over the entire time series. Simultaneously the thermally driven buoyancy loss vanishes more and more, leading to a transition from a $\mathscr{B}_{\mathrm{T}}$ - dominated net buoyancy loss to a $\mathscr{B}_{\mathrm{S}}$ - dominated net buoyancy gain region. This is also reflected in the buoyancy flux ratio (Figure 5 , upper right) that switched from a $\mathscr{B}_{\mathrm{T}}$ dominance $\left(\mathscr{B}_{\mathrm{T}} / \mathscr{B}_{\mathrm{S}}<-1\right)$ for the 1950 to 1980 's to a $\mathscr{B}_{\mathrm{S}}$ dominance $\left(\mathscr{B}_{\mathrm{T}} / \mathscr{B}_{\mathrm{S}}>-1\right)$ in the later decades. The positive correlation between anomalous annual $\mathscr{B}_{\mathrm{S}}$ $\left(\mathscr{B}_{\mathrm{T}}\right)$ and SAM (PDO) amounts to $0.46(0.39)$, both at the $99 \%$ significance level.

The $\Theta_{B}$ analysis shows that for Box 2 the area occupation in S4 decreases from more than $60 \%$ to about $20 \%$ while S5 (average 29\%) and S6 (average 17\%) occupation increases in parallel (Figure 5, lower panels). Based on repeated hydrographic observations, a warmer and more saline AAIW composition was found comparing the 1960s with recent years (Wong et al., 1999; Shaffer et al., 2000). The less dense water above the AAIW were found to be warmer and fresher (Boening et al., 2008).

Finally, the global buoyancy flux variability is shown in Figure 6. Compared to the magnitude in $\mathscr{B}$ variability in Boxes 1, 2, the magnitude of the global flux variability is small. The dominant source for $\mathscr{B}$ variability are the fluctuations in $\mathscr{B}_{\mathrm{T}}$ whilst the variability of $\mathscr{B}_{\mathrm{S}}$ is about 10 times smaller (Figure 6, upper left). During the first two decades (1950 to 1970) and the last two decades (mid 1990 to 2009), the $\mathscr{B}_{\mathrm{T}}$ buoyancy flux was anomalous high compared to the 1970 to 1990 decades.

The variability in global ocean areal occupation for the $\mathscr{B}_{\mathrm{T}}$ - dominated segments is $10 \%$, which is surprisingly large. The $\mathscr{B}_{\mathrm{T}}$ and $\mathscr{B}_{\mathrm{S}}$ combinations in $\mathrm{S} 3 / \mathrm{S} 8$ and in $\mathrm{S} 4 / \mathrm{S} 7$ compensate each other, explaining why the magnitude of the area average flux is small (Figure 6, upper left). For the transfer of air/sea flux variability into the ocean interior, not only the flux magnitude is important but the areal extent were net buoyancy loss occurs. The area occupation of $\Theta_{B}$ in S4 (S7) is positively (negatively) correlated with the PDO by 0.55 (both at the $99 \%$ significance level). Corresponding fluctuations in S3 and S5 are negatively and positively correlated, respectively, with the NAO at 0.31 and 0.55 (both at the $95 \%$ significance level).

A systematic shift during the 1960s/1970s as seen in S4/S7, has been identified in many atmospheric variables, such as rainfall, winds pattern, etc. (see Baines and Folland, 2007, for a summary). Baines and Folland (2007) identified the ocean/atmosphere system inherent internal variability to be the dominante cause for the shift. But other factors, such as greenhouse gas emissions, have been identified as well (Meehl et al., 2009). However, it remains unclear how much inconsistencies in the NCEP data sets contribute to generating such variability. These inconsistencies may be caused by numerous reasons, including the general lack of data in certain regions, the sudden improvement of the observatory network (e.g. satellite remote sensing), or shortcomings in parameterizing the atmospheric boundary layer.

\section{Conclusion}

Buoyancy fluxes $(\mathscr{B})$ at the ocean surface represent a combination of the haline and thermal forcing and therefore a joint interpretation of the haline $\left(\mathscr{B}_{\mathrm{S}}\right)$ and thermal $\left(\mathscr{B}_{\mathrm{T}}\right)$ buoyancy flux components is

(C) 0000 Tellus, 000, 000-000 
desirable when analysing $\mathscr{B}$ variability. In the past a simple ratio of $\mathscr{B}_{\mathrm{T}} / \mathscr{B}_{\mathrm{S}}$ has been presented as a diagnostic tool (e.g. Schmitt et al., 1989; Speer et al., 1995; Zhang and Talley, 1998), but a ratio has disadvantages, such as ambigutey, infinity problems, and asymmetric scaling. As such a ratio is not well suited for quantitative diagnostics.

Here we present a diagnostic tool, called the buoyancy flux angle $\left(\Theta_{B}\right)$, that combines $\mathscr{B}_{\mathrm{T}}$ and $\mathscr{B}_{\mathrm{S}}$ in a single quantity. $\Theta_{B}$ is divided into eight characteristic segments. Considering the areal occupation of each of the eight $\Theta_{B}$ segments, the temporal variability in $\mathscr{B}_{\mathrm{T}}$ and $\mathscr{B}_{\mathrm{S}}$ is analysed in a joint quantity.

NCEP reanalysis time series (1948 to 2009) of atmosphere and ocean surface parameters are used to illustrate the $\Theta_{B}$ analysis and to compare with results obtained by looking at $\mathscr{B}_{\mathrm{T}}$ and $\mathscr{B}_{\mathrm{S}}$ individually. Two important water mass formation regions of the global ocean are chosen for demonstration purposes: the subpolar North Atlantic (Box 1) and the eastern South Pacific (Box 2).

In Box 1, a pronounced freshening of surface waters has been reported and related to an increase in net precipitation (Reverdin et al., 2002; Josey and Marsh, 2005). The $\Theta_{B}$ analysis confirmed the freshening via a positive trend in area coverage of $\mathrm{S} 4$, which indicates that $\mathscr{B}_{\mathrm{T}}$ drives $\mathscr{B}$ but is opposed by $\mathscr{B}_{\mathrm{S}}$. Being positive (net freshwater gain) during most of the time, in 1969/1970 the areal averaged $\mathscr{B}_{\mathrm{S}}$ turned negative (evaporation exceeded net precipitation). By looking at the $\Theta_{B}$ time series (S3), we see that these 'exceptional' years were part of a multidecadal variability which is positively correlated with the Pacific Decadal Oscillation at 0.3. No significant correlation with the North Atlantic Oscialltion could be found for the S3 and S4 time series.

Box 2 is a key water mass formation area for Antarctic Intermediate Water. The area experienced a transition from being dominated by a $\mathscr{B}_{\mathrm{T}}$ driven net surface buoyancy loss to a $\mathscr{B}_{\mathrm{S}}$ driven net buoyancy gain. $\Theta_{B}$ analysis showed that the decrease in area with a thermal driven buoyancy loss (S4) was occupied in similar partitions from haline dominated buoyancy gain areas (S5 and S6). The area changes are correlated at -0.4 (S4) and +0.3 (S5 and S6) with the Southern Annular Mode.

For the global ocean area south of $70^{\circ} \mathrm{N}$ we found that the heat and freshwater buoyancy flux variability is small in magnitude, as expected when using a data set that has been forced to be nearly closed in global heat and freshwater fluxes. Nevertheless, $\Theta_{B}$ analysis revealed pronounced changes in the surface ocean area occupation, in particular of thermal buoyancy flux dominated loss and gain areas. These changes are likely associated with corresponding changes in the ventilating water masses.

Especially for ocean model simulations, the heat and freshwater forcing is crucial for experimental results. $\Theta_{B}$ offers a simple way for analyzing forcing data sets and allows to easier identify inconsistencies in the forcing fields. $\Theta_{B}$ analysis can be particularly useful when investigating the output of coupled ocean-atmosphere models as all input data needed to calculate $\Theta_{B}$ is available.

\section{Acknowledgments}

The NCEP Reanalysis data and NOAA Optimum Interpolation (OI) SST V2 data was provided by NOAA/OAR/ESRL PSD, Boulder, Colorado, USA, from their website at http://www.esrl.noaa.gov/psd/. This work is in part a contribution to the EuroSITES project. Partial support from the European Commission under contract SIP3-CT-2003-502885 is gratefully acknowledged. Critical suggestions by three anonymous reviewers and the editor greatly improved the presentation of this work. 


\section{REFERENCES}

Badin, G. and Williams, R. 2010. On the buoyancy forcing and residual circulation in the Southern Ocean: The feedback from Ekman and eddy transfer. J. Phys. Oceanogr. 40, 295-310.

Badin, G., Williams, R. and Sharples, J. 2010. Water mnass transformation in shef seas. J. Mar. Res. 68, $189-214$.

Baines, P. and Folland, C. 2007. Evidence for a Rapid Global Climate Shift across the Late 1960s. Journal of Climate 20, 2721-2744.

Boening, C. W., Dispert, A., Visbeck, M., Rintoul, S. R. and Schwarzkopf, F. U. 2008. The response of the Antarctic Circumpolar Current to recent climate change. Nature Geoscience 1(12), 864-869.

Curry, R. and Mauritzen, C. 2005. Dilution of the northern North Atlantic in recent decades. Science 308, 17721774.

Emery, W. J. and Meincke, J. 1986. Global water masses: summary and review. Oceanol. Acta 9(4), 383-391.

Fairbanks, R. 1989. A 17,000-year glacio-eustatic sea level record: influence of glacial melting rates on the Younger Dryas event and deep-ocean circulation. Nature 342, 637-642.

Garrett, C., Speer, K. and Tragou, E. 1995. The relationship between water mass formation and the surface bouyancy flux, with application to phillips' red sea model. J. Phys. Oceanogr. 25, 1696-1705.

Hanawa, K. and Talley, L. D.: 2001, Academic Press, International Geophysics Series, chapter Mode Waters, pp. 373-386.

Hurrell, J. W. and Deser, C. 2009. North Atlantic climate variability: The role of the North Atlantic Oscillation. J. Mar. Res. 78(1), 28-41.

Josey, S. and Marsh, R. 2005. Surface freshwater flux variability and recent freshening of the North Atlantic in the eastern subpolar gyre. Journal of Geophysical Research 110(C05008), doi:10.1029/2004JC002521.

Kalnay, E., Kanamitsu, M., Kistler, R., Collins, W., Deaven, D., Iredell, M. and co auhors 1996. The NCEP/NCAR 40-year reanalysis project. Bull. Amer. Meteor. Soc. 77, 437-470.

Large, W. G. and Nurser, A. J. G.: 2001, Academic Press, International Geophysics Series, chapter Ocean Surface Water Mass Transformation, pp. 317-336.

Levitus, S., Burgett, R. and Boyer, T. 1994. World Ocean Atlas, Vol. 3, Salinity, Technical report, NOAA Atlas NESDIS 3, U.S. Gov. Printing Office, Washington, D.C.

Mamayev, O. I. 1975. Temperature-salinity analysis of world ocean waters Mamayev, O. I. Elsevier, 374 pp.

Marshall, D. 1997. Subduction of water masses into an eddying ocean. J. Mar. Res. 55, 201-222.

Marshall, G. 2003. Trends in the Southern Annular Mode from observations and reanalyses. J. Climate 16, 41344143.

McCartney, M. S.: 1977, Vol. 24 (Suppl.)), M. Angel, Pergamon Press, Oxford, U.K., chapter Subantarctic Mode Water, pp. 103-119.

McCartney, M. S. 1982. The subtropical recirculation of Mode Waters. J. Mar. Res. 40(Suppl.), 427-464.

Meehl, G., Hu, A. and Santer, B. 2009. The Mid-1970s Climate Shift in the Pacific and the Relative Roles of Forced versus Inherent Decadal Variability. Journal of Climate 22, 780-792.

Nurser, A. J. G., Marsh, R. and Williams, R. 1999. Diagnosing formation rates of water masses from air-sea fluxes and surface mixing. J. Phys. Oceanogr. 29, 1468-1487.

Reverdin, G., Durand, F., Mortensen, J., Schott, F., Valdimarsson, H. and Zenk, W. 2002. Recent changes in the surface salinity of the North Atlantic subpolar gyre. J. Geophys. Res. 107(C12)(8010), doi:10.1029/2001JC001010.

Reynolds, R. W., Rayner, N. A., Smith, T. M., Stokes, D. C. and Wang, W. 2002. An Improved In Situ and Satellite SST Analysis for Climate. Journal of Climate 15, 1609-1625.

Schmitt, R. W., Bogden, P. S. and Dorman, C. E. 1989. Evaporation minus precipitation and density fluxes for the North Atlantic. J. Phys. Oceanogr. 19, 1208-1221.

Shaffer, G., Leth, O., Ulloa, O., Bendtsen, J., Daneri, G., Dellarossa, V., Hormazabal, S. and Sehlstedt, P. 2000. Warming and circulation changes in the eastern South Pacific Ocean. Geophys. Res. Let. 27, $1247-1250$.

Smith, T., Reynolds, R. and Peterson, T. 2008. Improvements to NOAA's Historical merged Land-Ocean Surface Temperature Analysis (1880-2006). Journal of Climate 21, 2283-2296.

Speer, K. 1997. A note on average cross-isopycnal mixing in the North Atlantic Ocean. Deep-Sea Res. 44(12), 19811990.

Speer, K. G., Isemer, H.-J. and Biastoch, A. 1995. Water mass formation from revised COADS data. J. Phys. Oceanogr. 25, 2444-2457.

Speer, K., Rintoul, S. R. and Sloyan, B. M. 2000. The diabatic Deacon Cell. J. Phys. Oceanogr. 30(12), 3212-3222. Sverdrup, H. U., Johnson, M. W. and Fleming, R. H. 1942. The Oceans: There physics, chemistry, and general biology Sverdrup, H. U., Johnson, M. W. and Fleming, R. H. Prentice-Hall, Englewood Cliffs, N.J., USA.

Tomczak, M. and Godfrey, S. 1994. Regional Oceanography: An Introduction Tomczak, M. and Godfrey, S. Pergamon Press, Oxford, UK.

(C) 0000 Tellus, 000, 000-000 
Tziperman, E. 1986. On the role of interior mixing and air-sea fluxes in determining the stratification and circulation of the oceans. J. Phys. Oceanogr. 16, 680-693.

Vellinga, M. and Wood, R. A. 2002. Global Climatic Impacts of a Collapse of the Atlantic Thermohaline Circulation. Climatic Change 54(3), 251-267.

Walin, G. 1982. On the relation between sea-surface heat flow and thermal circulation in the ocean. Tellus 34, 187-194.

Wong, A. P. S., Bindoff, N. L. and Church, J. A. 1999. Large scale freshening of intermediate waters in the Pacific and Indian Oceans. Nature 400, 440-443.

Zhang, H.-M. and Talley, L. D. 1998. Heat and buoyancy budgets and mixing rates in the upper thermocline of the Indian and global Oceans. J. Phys. Oceanogr. 28, 1961-1978.

Zhang, Y. Z., Wallace, J. M. and Battisti, D. S. 1997. ENSO-like interdecadal variability: 1900-1993. J. Climate 10, 1004-1020. 


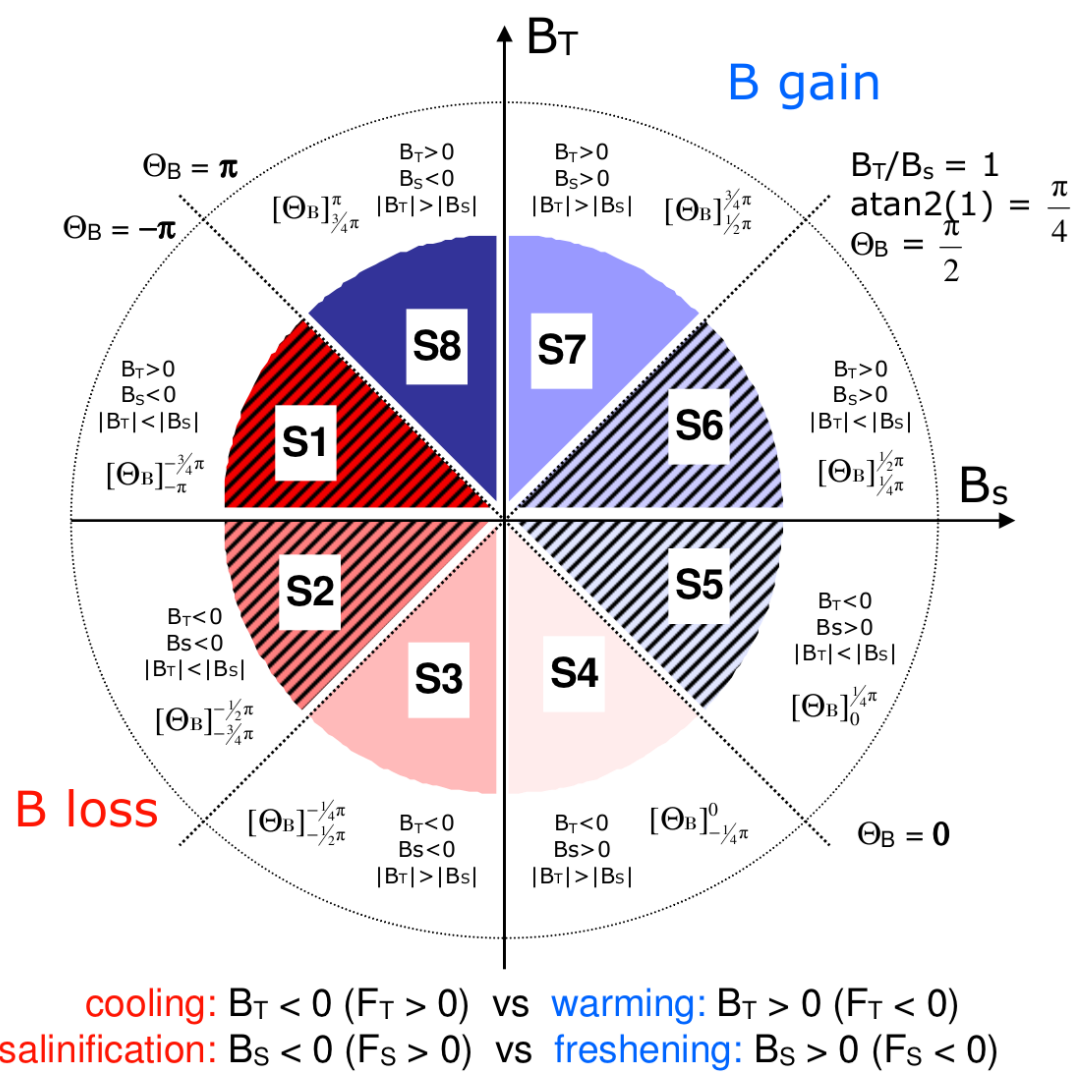

Figure 1. Schematic of buoyancy flux angle, $\Theta_{B}$, relative to the buoyancy flux components $\left(\mathscr{B}_{\mathrm{T}}\right.$ and $\left.\mathscr{B}_{\mathrm{S}}\right)$. The numbers indicate the eight segments $\mathrm{S} 1$ to $\mathrm{S} 8$ as referenced in Table 1 and in the text. Redish segments indicate total buoyancy loss, $\mathscr{B}_{\mathrm{S}}$ dominated segments are hatched. In each segment, the respective $\mathscr{B}_{\mathrm{T}}, \mathscr{B}_{\mathrm{S}}$ composition and $\Theta_{B}$ ranges are given.

(c) 0000 Tellus, 000, 000-000 
(a)
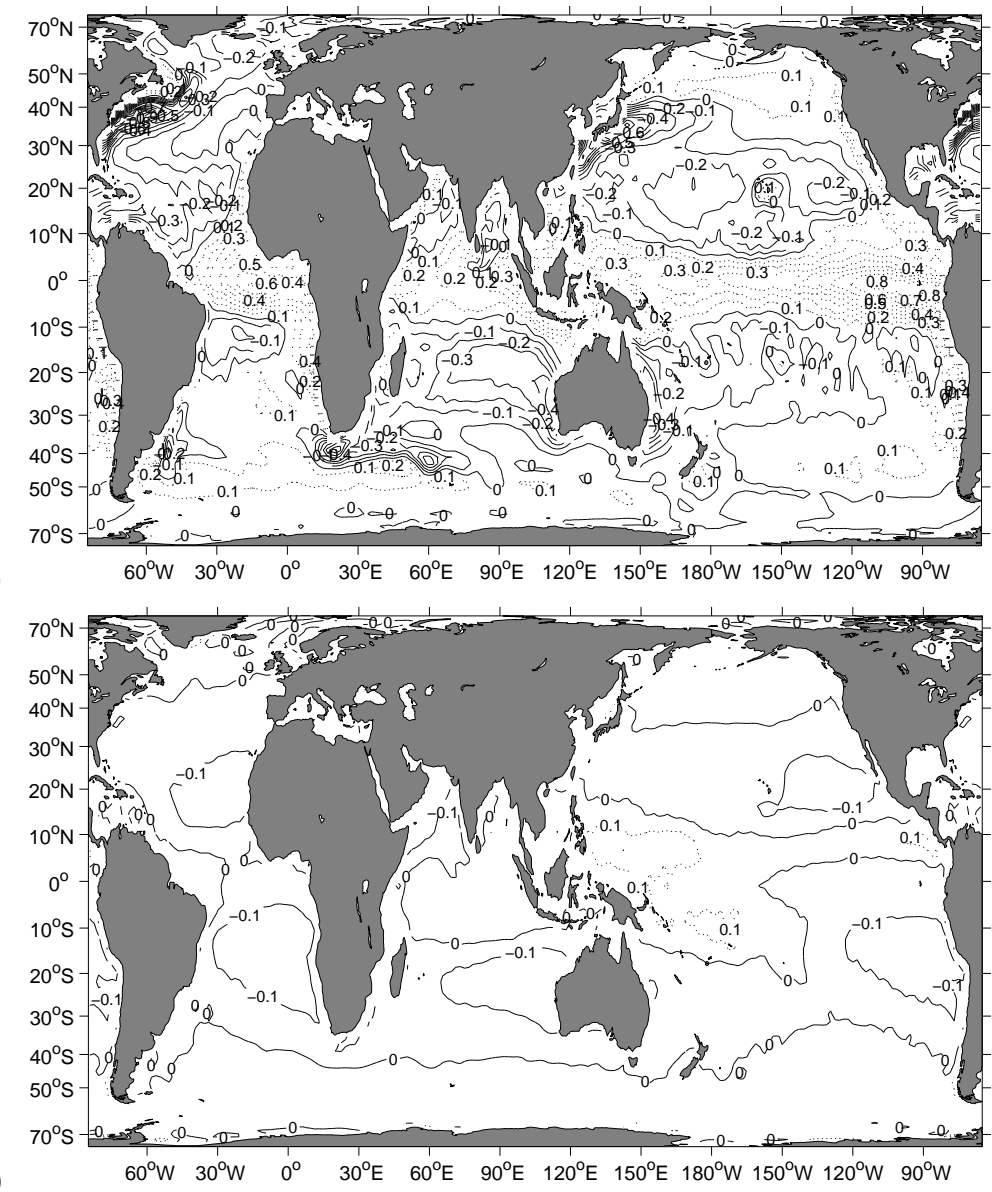

(b)

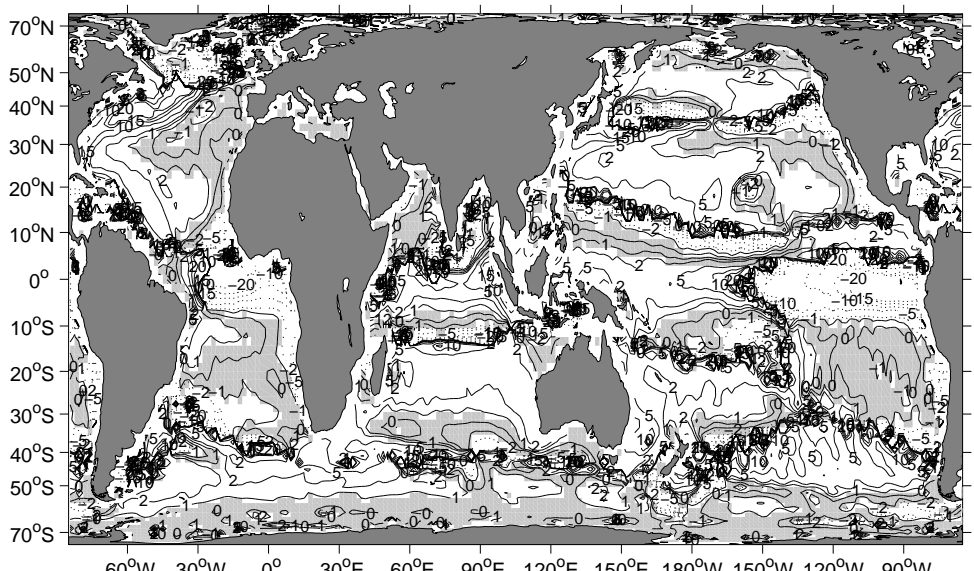

(c)

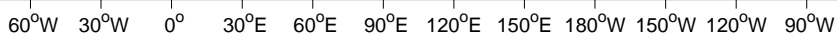

Figure 2. Long-term mean distributions of (a) thermal buoyancy flux $\left(\mathscr{B}_{\mathrm{T}}\right)$ and (b) haline buoyancy flux $\left(\mathscr{B}_{\mathrm{S}}\right)$. Note that the same contour interval was used in both panels $(0.1 \mathrm{~W} / \mathrm{kg})$, and dashed lines indicate buoyancy gain. (c) Buoyancy flux ratio $\left(\mathscr{B}_{\mathrm{T}} / \mathscr{B}_{\mathrm{S}}\right)$ where grey shading indicates freshwater flux dominates buoyancy flux, dashed lines indicate negative ratios. 


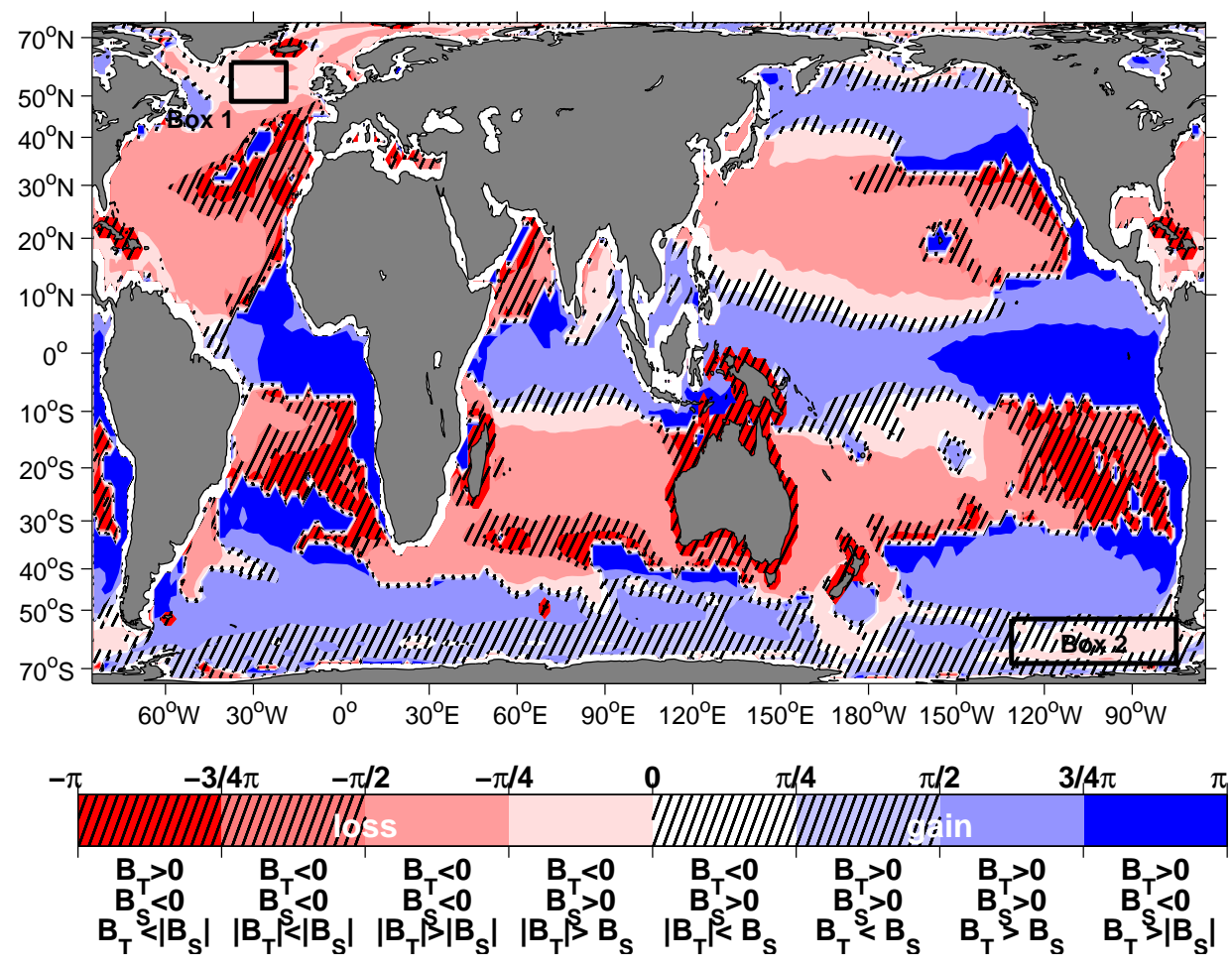

Figure 3. Long-term mean distribution of buoyancy flux angle $\Theta_{B}$. Boxes used for time series analysis are indicated by black frames. 

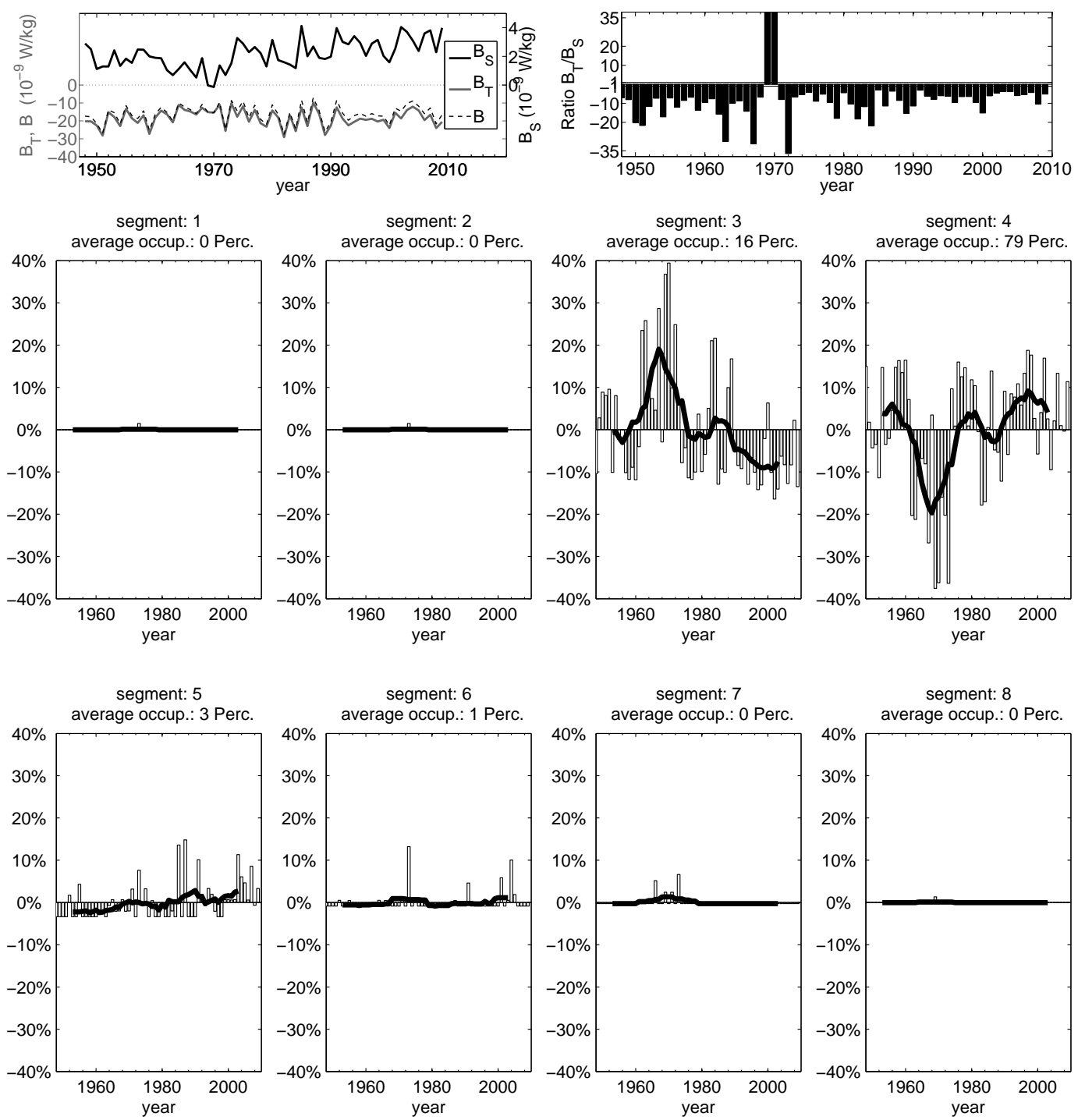

Figure 4. North Atlantic subpolar gyre Box 1 (see Figure 3): Time series (1948-2009) of (upper left) area averaged buoyancy fluxes $\mathscr{B}_{\mathrm{T}}, \mathscr{B}_{\mathrm{S}}$, and $\mathscr{B}$ (note difference in scales); (upper right) buoyancy flux ratio $\mathscr{B}_{\mathrm{T}} / \mathscr{B}_{\mathrm{S}}$; (lower eight panels) area occupation of the eight $\Theta_{B}$ segments S1 to S8. The black line indicates the 11-year running mean. The time averaged area occupation of each segment for the box is given in the title 

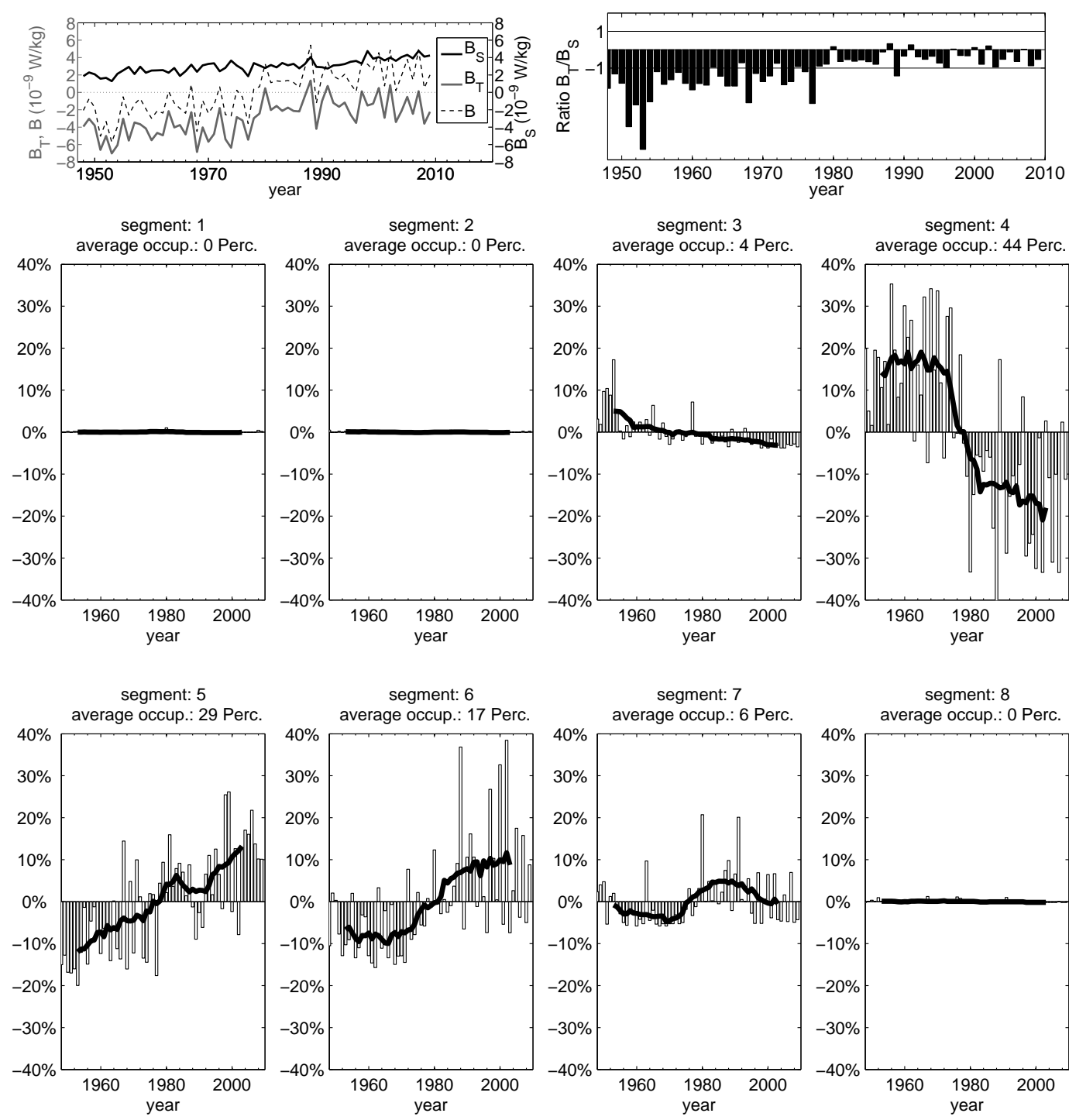

Figure 5. As Figure 4, but for South Pacific Box 2 (see Figure 3) 

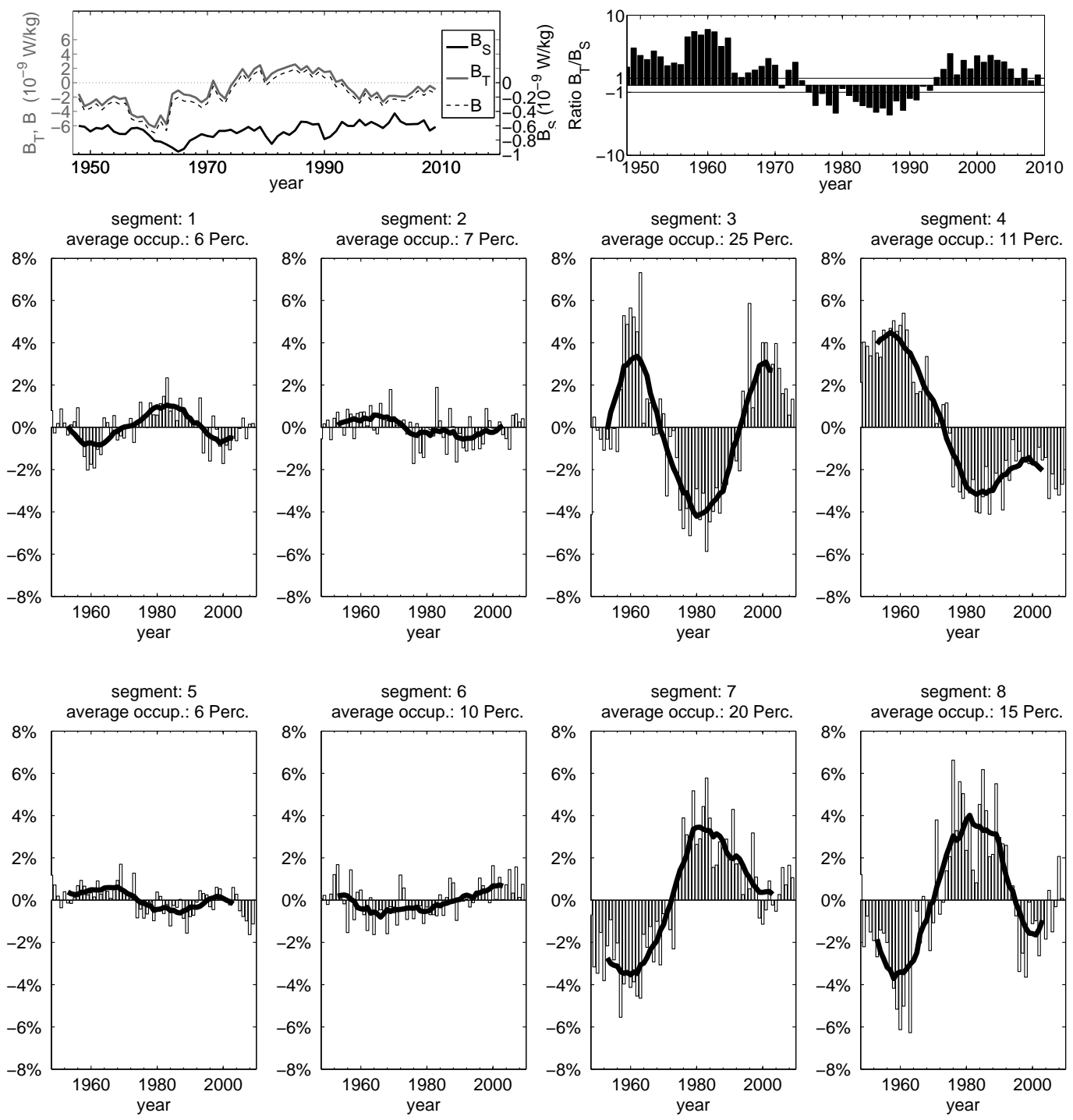

Figure 6. As Figure 4, but for the global ocean south of $70^{\circ} \mathrm{N}$. 
Table 1. Eight segments of $\Theta_{B}$ and associated sign and ratios of the thermal ( $\mathscr{B}_{\mathrm{T}}$ ) and haline ( $\left.\mathscr{B}_{\mathrm{S}}\right)$ buoyancy flux components (compare also Figure 1). Last row give the percentage of area occupation in the long-term mean as derived from the NCEP reanalysis data.

\begin{tabular}{ccccccccc} 
& \multicolumn{4}{c}{ buoyancy loss } & \multicolumn{4}{c}{ buoyancy gain } \\
\hline \multirow{2}{*}{ segment } & $\mathrm{S} 1$ & $\mathrm{~S} 2$ & $\mathrm{~S} 3$ & $\mathrm{~S} 4$ & $\mathrm{~S} 5$ & $\mathrm{~S} 6$ & $\mathrm{~S} 7$ & $\mathrm{~S} 8$ \\
\hline \multirow{2}{*}{$\Theta_{B}$} & $-\pi$ & $-3 \pi / 4$ & $-\pi / 2$ & $-\pi / 4$ & 0 & $\pi / 4$ & $\pi / 2$ & $3 \pi / 4$ \\
& to & to & to & to & to & to & to & to \\
& $-3 \pi / 4$ & $-\pi / 2$ & $-\pi / 4$ & 0 & $\pi / 4$ & $\pi / 2$ & $3 \pi / 4$ & $\pi$ \\
\hline $\mathscr{B}_{\mathrm{T}}$ & $>0$ & $<0$ & $<0$ & $<0$ & $<0$ & $>0$ & $>0$ & $>0$ \\
$\mathscr{B}_{\mathrm{S}}$ & $<0$ & $<0$ & $<0$ & $>0$ & $>0$ & $>0$ & $>0$ & $<0$ \\
$\left|\mathscr{B}_{\mathrm{T}}\right|>\left|\mathscr{B}_{\mathrm{S}}\right|$ & no & no & yes & yes & no & no & yes & yes \\
\hline Global Area $(\%)$ & 6 & 7 & 25 & 11 & 6 & 10 & 20 & 15
\end{tabular}

(C) 0000 Tellus, 000, 000-000 